\title{
Empowering prosumers to trade renewable energy can benefit the individual, the community, and the grid
}

\section{Alejandro Pena-Bello}

University of Geneva https://orcid.org/0000-0001-5518-8467

David Parra ( $\sim$ David.Parra@unige.ch )

University of Geneva https://orcid.org/0000-0001-7196-4569

\section{Mario Herberz}

https://orcid.org/0000-0001-8683-5604

\section{Verena Tiefenbeck}

Friedrich-Alexander-Universität

\section{Martin Patel}

University of Geneva

Ulf Hahnel

University of Geneva https://orcid.org/0000-0002-0595-5899

\section{Article}

Keywords: Peer-to-peer Exchange, Solar Power Trading, Decision-making Strategies, Community Autarky, Grid Level Stress

Posted Date: March 2nd, 2021

DOl: https://doi.org/10.21203/rs.3.rs-234650/v1

License: (c) (i) This work is licensed under a Creative Commons Attribution 4.0 International License.

Read Full License

Version of Record: A version of this preprint was published at Nature Energy on December 13th, 2021. See the published version at https://doi.org/10.1038/s41560-021-00950-2. 


\title{
Empowering prosumers to trade renewable energy can benefit the individual, the community, and the grid
}

\author{
authors blind for review
}

\begin{abstract}
Peer-to-peer (P2P) exchange of renewable energy is an attractive option to engage and empower citizens to actively participate in the energy transition. Whereas previous research has provided techno-economic models and technological solutions to enable P2P energy trading, little is yet known about citizen preferences for solar power trading. Importantly, impacts of community members' trading decisions across scales such as individual electricity bills, community autarky and grid stability remain unknown. Here, we assess actual P2P trading strategies based on an experimental study with German homeowners and simulate how retrieved decision-making strategies impact the performance of P2P communities across the three scales. Our findings suggest that community autarky is higher in P2P communities than in self-consumption communities, even if self-consumption communities search to maximize autarky (an autarky paradox). We show that actual prosumer decision-making may lead to benefits at the individual (reduced energy bills), community (higher community autarky), and grid level (reduced stress).
\end{abstract}

Renewable energy communities (RECs) have the potential to play a key role in the transition towards clean and affordable energy. The European Union, for instance, has put RECs in the spotlight of its energy strategy (referred to as Clean Energy for all European Package) and enacted the right of citizens to consume, store and sell self-generated renewable energy, either individually or in communities ${ }^{1}$. RECs can be defined as renewable-based and distributed energy systems ${ }^{2}$, embedded within or close to the consumption centers, where members share several attributes (e.g., space and network) and/or interests (e.g., renewable electricity supply and decarbonization), and actively participate in the project across one or more phases ${ }^{3}$. Compared to centralized systems, RECs are more effective in balancing local renewable energy supply and demand through decentralized storage and flexible demand ${ }^{4,5}$. Additionally, the community scale has proven to be more cost-effective than single dwellings for the deployment of some technologies such as energy storage, resulting in lower levelized cost ${ }^{5}$. RECs can therefore enable local flexibility to reduce grid stress 6 .

Besides their technological, environmental, and economic potential, RECs can bring benefits at the social level, as community concepts enable citizens to actively engage in the energy transition ${ }^{3}$. Several types of RECs have been discussed in the previous literature such as cooperatives, self-consumption communities, virtual power plants, energy hubs, and peer-to-peer (P2P) electricity trading communities ${ }^{7,8}$. Among them, P2P communities can enable further citizen empowerment due to the involvement of community members in real time operation ${ }^{9}$. In $\mathrm{P} 2 \mathrm{P}$ communities, prosumers (i.e., agents that both consume and produce energy) can buy and sell self-generated electricity on a local market. Furthermore, PV-coupled batteries provide prosumers with extra flexibility by enabling them to increase their own autarky, or to sell electricity to other community members at a price higher than the usual feed-in tariff (FiT, usually set by national/state governments). In organic P2P electricity markets (i.e., fully distributed structures that rely on grassroots initiatives from prosumers and in which peers can directly trade electricity among each other), members become an integral part of the community decision-making process, determining when and how renewable energy is shared and distributed within the community ${ }^{10,11}$.

A large majority of the public endorses P2P energy community schemes and is, in general, willing to participate in associated projects. Independent studies administered in Europe indicate willingness-to-participate rates between $74.5 \%$ and $79 \%{ }^{12-14}$. Moreover, $89.5 \%$ of citizens would prefer P2P electricity trading to be based on their individual preferences (either administered manually or through user-centered algorithms) over an entirely automatic decision process, based on a representative sample of 1000 Swiss citizens (see Section 1 in Supplementary Information-SI). However, trading decisions in the context of a P2P community are complex as various factors such as dynamic electricity prices, state of charge (SOC) of batteries, and PV generation forecasts should be considered. These decisions are further 
subject to trade-offs, since selling self-generated electricity when market prices are high can be financially attractive and contribute to increased renewable energy consumption at the community level, but this decision may also reduce individual autarky. In contrast, prioritizing autarky at the individual level may lead to less financial benefits in addition to a reduced community contribution. Thus, we hypothesize that optimal trading within the indicated decision window (i.e., neither too much, nor too little trading) may result in benefits at the individual, community and grid level, including reduced stress on the local grid. The intriguing question is, however, whether citizens are capable to make decisions that lead to benefits at the outlined levels or whether they are more likely to evoke market situations that may be suboptimal for them, the community, and the grid.

The existing scientific literature on P2P electricity trading has not answered this question yet. Previous studies on P2P energy communities have addressed techno-economic research, for instance underlying technologies ${ }^{15,16}$, and the pricing mechanisms ${ }^{17,18}$. User behavior has been reported for field trials but not used for the design and modeling of P2P communities ${ }^{9}$. Instead, community members have been considered and modeled as rational agents with exclusively economic interests ${ }^{15-18}$. For other aspects of the energy transition, integrating human decision-making preferences and behavior has already yielded considerable improvements in estimations ${ }^{19,20}$, but to the best of our knowledge, such actual decision data has not yet been integrated into energy modelling of P2P communities. This reductive view on human preferences and decision strategies is at odds with theories and empirical findings from the psychological science, illustrating that human preferences and decisions are not solely grounded in financial aspirations and largely deviate from assumptions made by normative economic theory ${ }^{21}$. Moreover, recent research on P2P energy trading has illustrated that prosumers vary in their preferences and apply different decision-making strategies in P2P decision scenarios rather than responding in a uniform fashion ${ }^{12}$. Thus, we argue that integrating actual human preferences and $\mathrm{P} 2 \mathrm{P}$ decision strategies in energy modelling can result in more realistic projections of the potential of $\mathrm{P} 2 \mathrm{P}$ communities for the individual, the community, and the grid ${ }^{22}$. Finally, such human-centered modeling is stronger in line with the principal idea that $\mathrm{P} 2 \mathrm{P}$ communities foster social empowerment as well as with citizens' preferences to become an active part of the $\mathrm{P} 2 \mathrm{P}$ decision process ${ }^{23}$.

In this article, we develop a P2P electricity community model incorporating experimental data on actual prosumer preferences and decision strategies concerning P2P electricity trading. Decision-making data were collected in Germany, the European country with the highest PV capacity ${ }^{24}$. Prosumer preferences were derived from an experimental study with 254 German homeowners willing to participate in P2P communities in order to assess individual P2P trading decisions as a function of the $\mathrm{P} 2 \mathrm{P}$ market prices, the SOC of privately owned batteries, and forecast of upcoming PV generation. Prosumers' actual decisions for each possible combination of factors (i.e., trading situations) were integrated into an open-source model of $\mathrm{P} 2 \mathrm{P}$ communities and simulated throughout a year to analyze the influences of human decision-making within a $\mathrm{P} 2 \mathrm{P}$ community on techno-economic indicators. We created a dynamic price structure, reflecting demand and supply at the point of decision-making, to model electricity prices in the P2P community.

We focus on local solar communities (i.e., communities with distributed PV located behind a point of common coupling), including both prosumers (with PV or with PV-coupled battery) and traditional consumers. In order to capture the effectiveness of the assessed decision-making strategies for the individual, the community and the grid and to provide recommendations for grid-friendly prosumer empowerment, we compare $\mathrm{P} 2 \mathrm{P}$ communities with self-consumption communities on the same basis, i.e. with the same technology characteristics and penetration. In the latter, community members aim to maximise the community autarky to avoid PV electricity exports rewarded at low prices corresponding to the FiT, but have no opportunity to trade energy from a shared energy storage device. This comparison allows us to benchmark the impacts and trade-offs of actual human decision-making preferences and strategies towards P2P trading for both, prosumers and traditional consumers on individual bills, as well as on self-consumption and autarky at the individual and community level. Moreover, we account for grid exchanges in terms of maximum power imported from and exported to the grid, and for the so-called duck curve, which represents a major challenge for grid management due to sudden ramping up and down of conventional generation to compensate the inherent loss of PV generation and to match supply and demand, in particular at sunset and sunrise ${ }^{25}$. We model both, P2P and self-consumption communities with 100 households in Germany. Considering the future-oriented nature of P2P communities, we assume a baseline scenario with $50 \% \mathrm{PV}$ penetration and $25 \%$ battery penetration. In order to get robust results, each community configuration was simulated 1000 times, randomly selecting the community members from the German sample. Results for other community sizes, PV and battery penetrations are displayed in Figures 4 and 5 of the SI, with similar outcomes. 

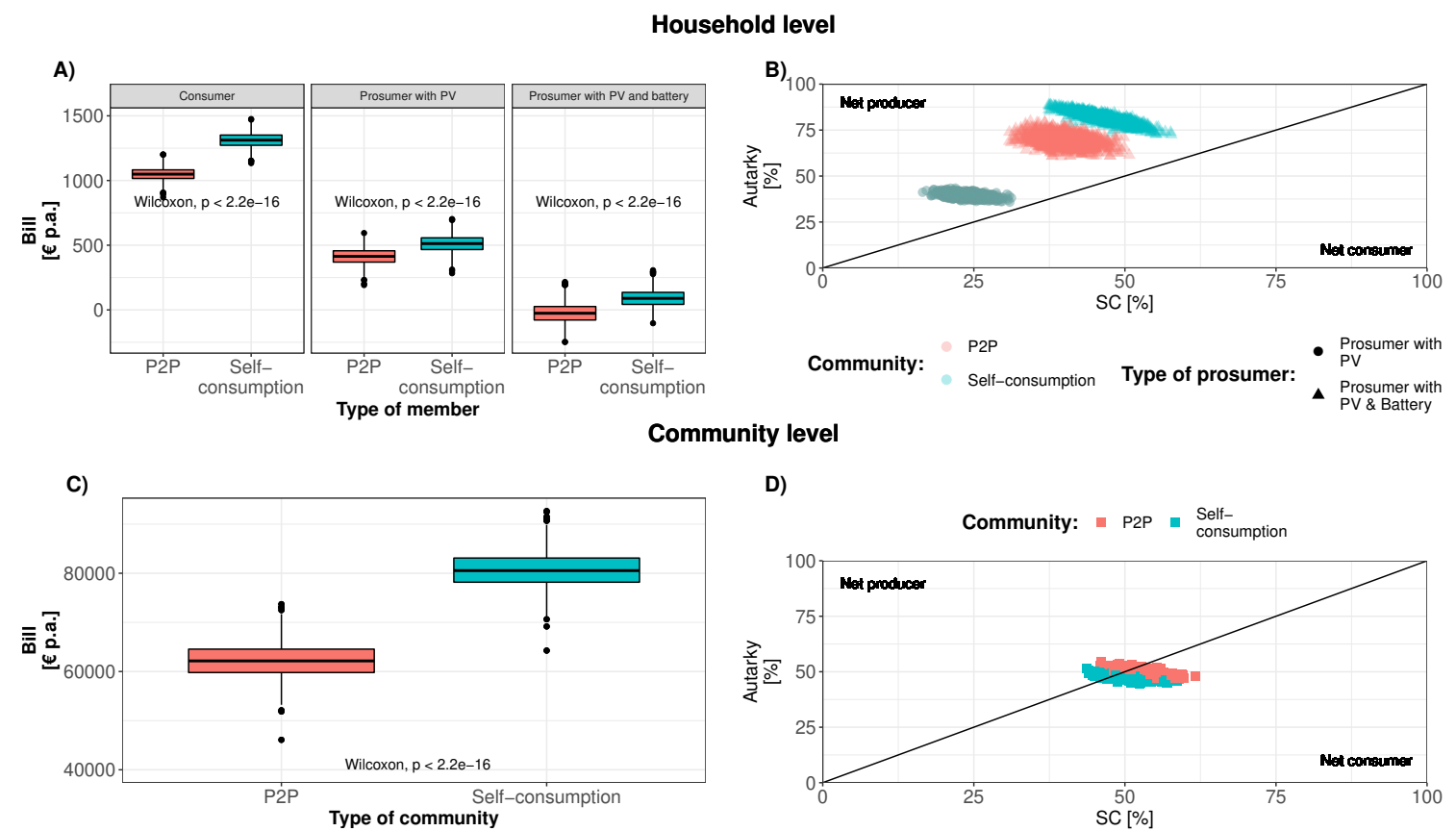

Figure 1. Results of the community modeling including prosumer preferences in $P 2 P$ communities ( $N=1000)$ : A) Annual bill at the individual level depending on the type of the community member; B) Energy matching chart (i.e., a graphical approach to assess matching between PV electricity generation and electricity demand, using self-consumption and autarky to visualize improved matching with energy storage and load shifting) at the individual level;C) Aggregated bill at the community level; D) Energy matching chart at the community level. The diagonal line represents the net zero energy households. Net producers of electricity are above the line and net consumers are below.

\section{Impact of prosumer decision-making at the individual level.}

Our findings show that P2P energy trading based on actual prosumer trading strategies lead to economic benefits for prosumers with PV-coupled batteries, but also for prosumers with PV only and for traditional consumers. Figure 1A illustrates that annual electricity bills are reduced for every type of community member in a P2P community compared to the self-consumption community. The largest reduction, corresponding to a median value of $260 €$ p.a., is for traditional consumers that incur in high electricity costs because of no PV generation. Prosumers with PV only are the community members with the lowest annual bill reduction compared to a self-consumption community, with a median difference of $100 €$ p.a. This amount slightly increases to $115 €$ p.a. for prosumers with batteries. For all type of consumers, the differences between a $\mathrm{P} 2 \mathrm{P}$ community and a self-consumption community are statistically significant $(p-$ values $\leq 0.001)$.

Figure 1B presents the distribution of the average self-consumption (SC) and average autarky for prosumers in P2P and self-consumption communities. For households with PV-coupled batteries both indicators are significantly reduced in a P2P community (6.6 percent points and 12 percent points, respectively) due to the extra electricity traded from batteries. For households with only PV, the indicators remained unchanged (no trading). Furthermore, we notice that the graphical representation of autarky versus self-consumption results exceeds the diagonal line, which corresponds to a net zero building on an annual basis, for both type of communities. This implies that prosumers are net producers of electricity, i.e., their aggregated annual PV generation is higher than their aggregated annual electricity consumption ${ }^{26}$.

\section{Impact of prosumer decision-making at the community level.}

Boxplots of annual community electricity bills are shown in Figure 1C, which illustrates that P2P trading also brings higher value at the community level, since the annual community aggregated bill is reduced by $22.8 \%$ (equivalent to $18390 €$ p.a.), compared to a self-consumption community (median values of the distribution, $p-$ values $\leq 0.001$ ). This important community value can be quantified through the benefit index ${ }^{18}$ (see Methods) which measures the percentage 


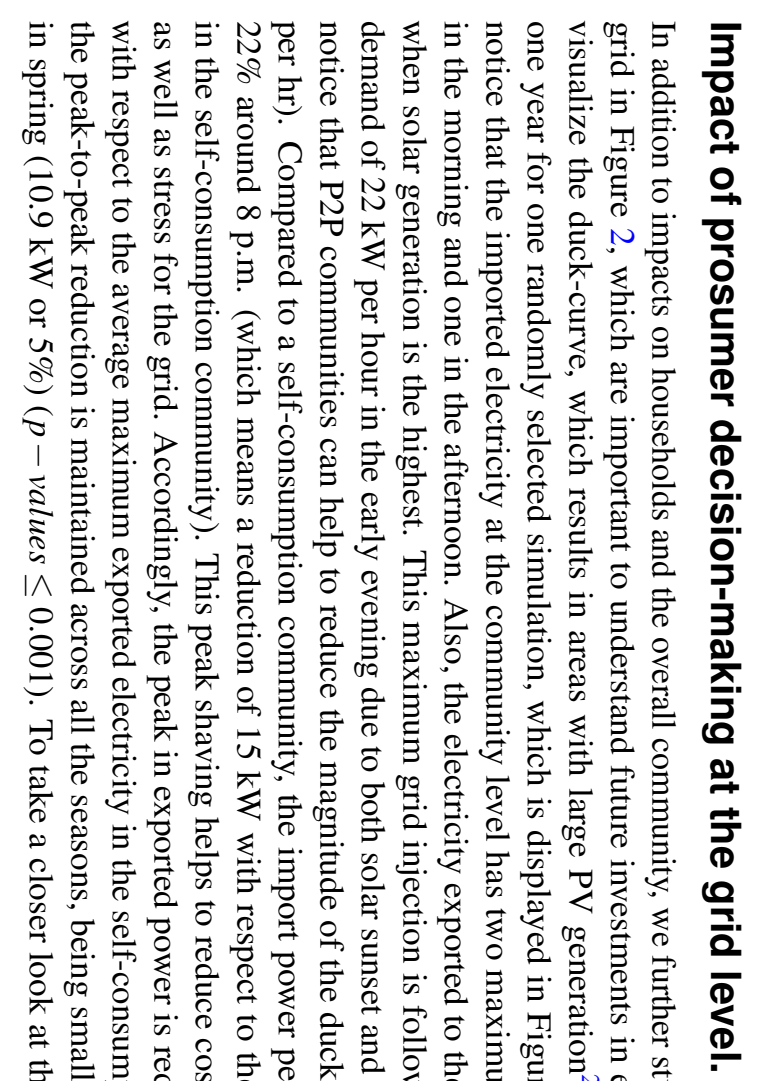

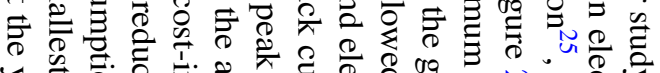

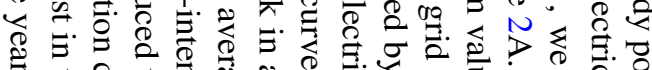

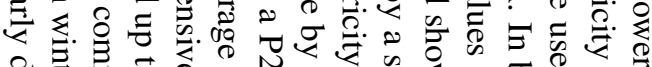

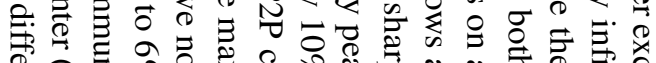

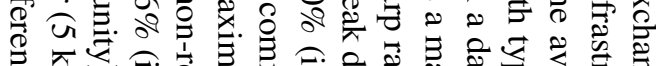

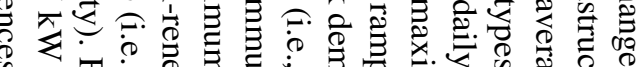

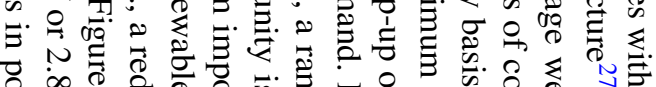

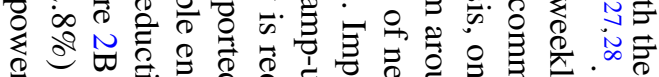

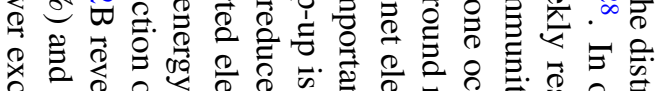

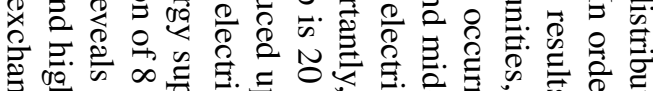

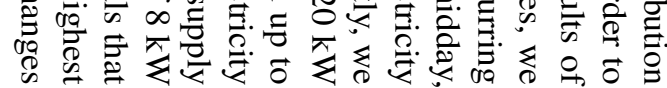
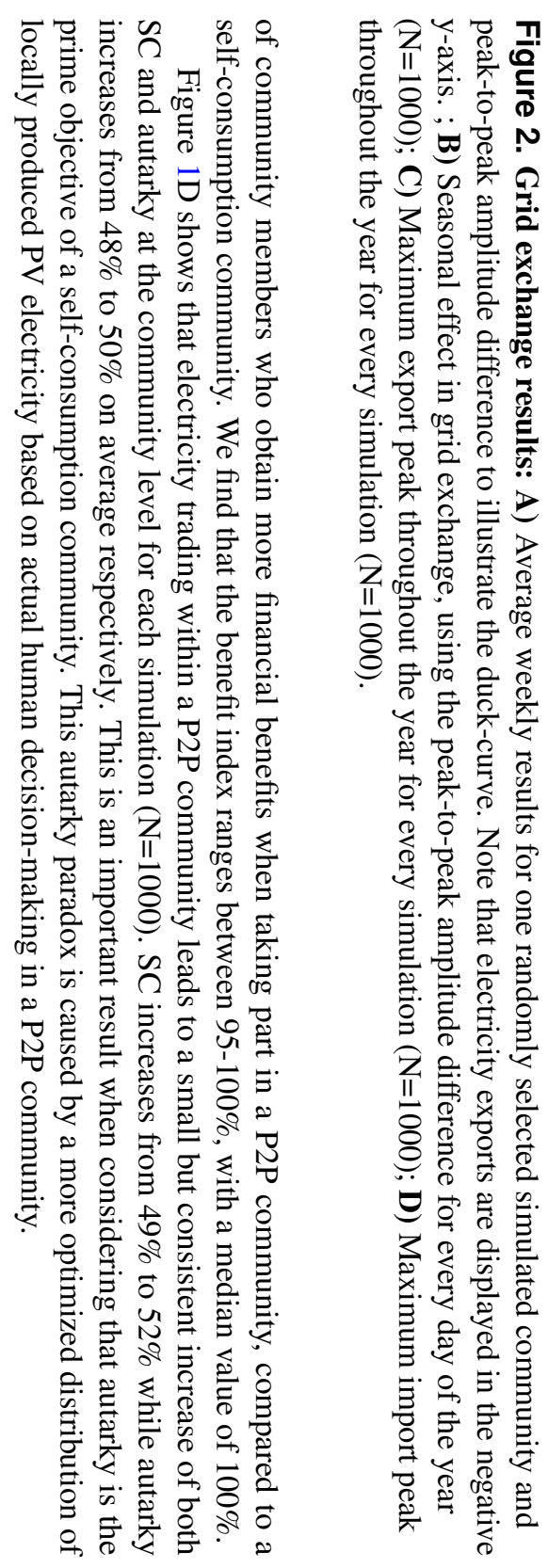
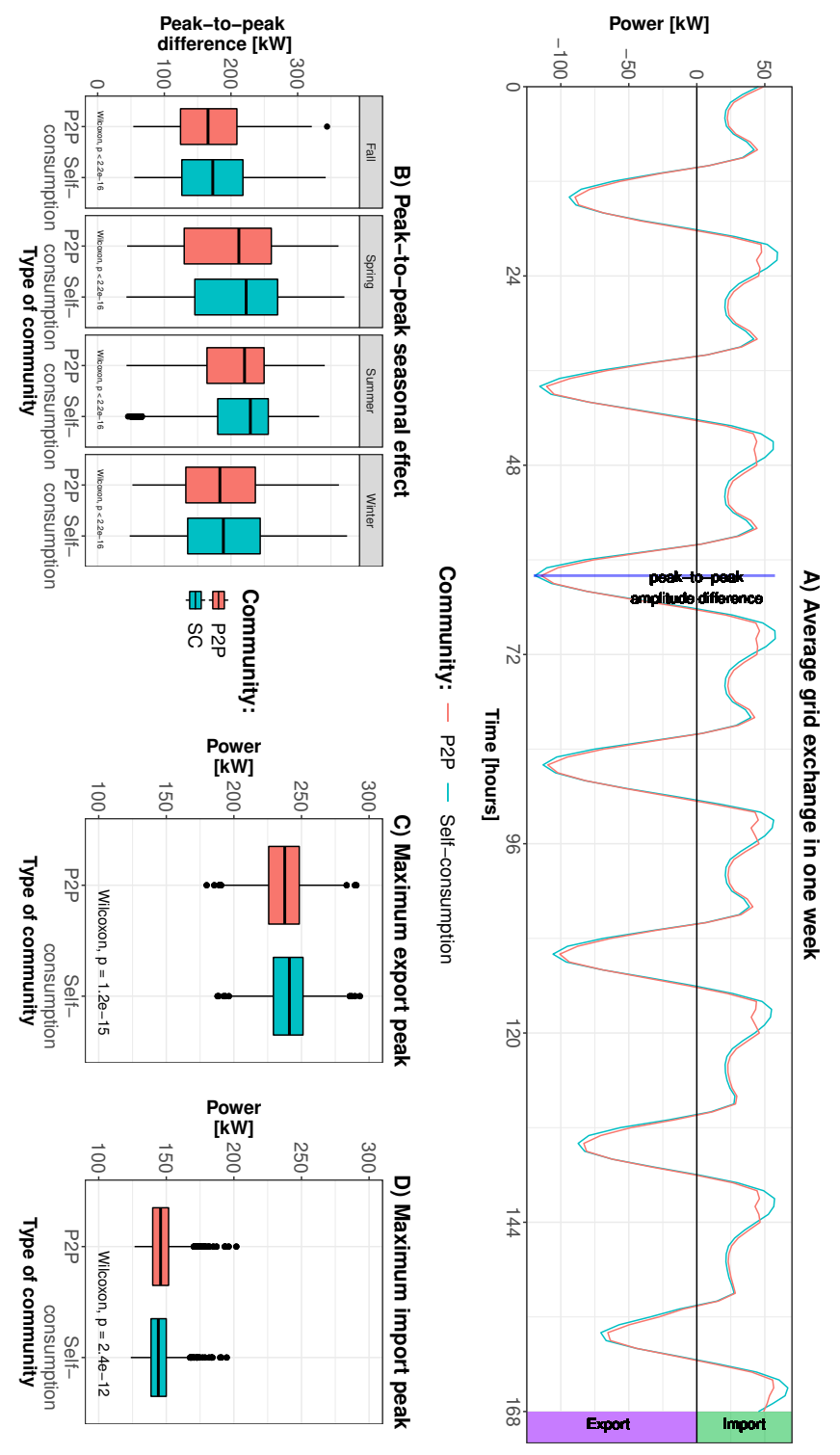

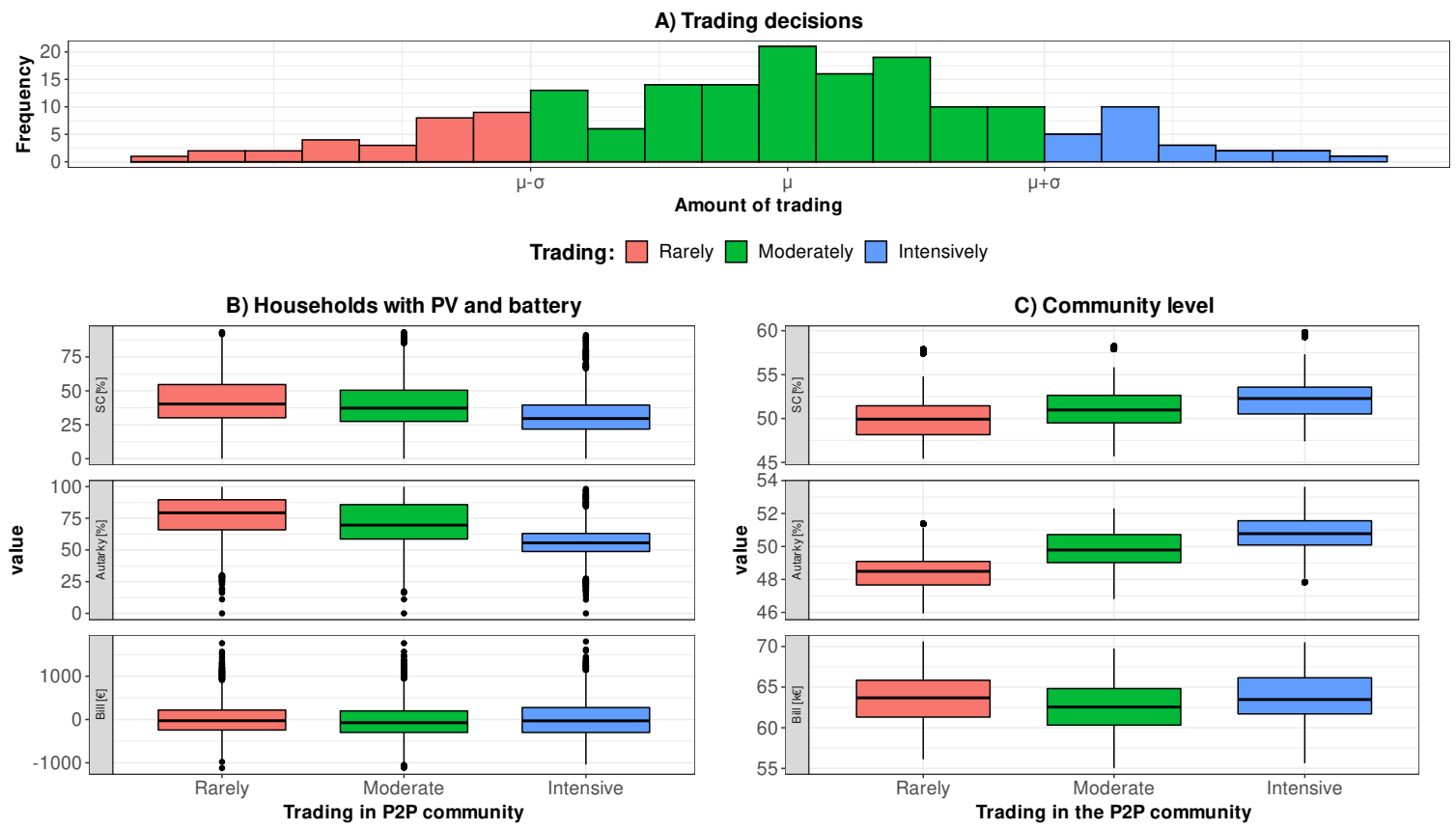

Figure 3. Results of the community modeling for communities with different patterns of trading (N=100): A) Histogram of trading decisions extracted from the survey; B) Self-consumption, autarky and annual bill for households with PV-coupled batteries; C) SC, autarky and annual bill at the community level.

with the grid, we use peak-to-peak amplitude differences per season for one year in a randomly selected simulation. Taken the maximum import peak across the entire year for the community (see Figure 2C), the maximum export peak is slightly higher in $\mathrm{P} 2 \mathrm{P}$ communities when compared to the self-consumption community, with a median difference of $1.7 \mathrm{~kW}$ ( $p-$ values $\leq 0.001)$. On the contrary, the maximum import peak (see Figure $2 \mathrm{D}$ ) is slightly lower in P2P communities, reaching a median difference of $-3.4 \mathrm{~kW}$ across the year.

\section{Analysis of prosumer decision strategies: optimal trading window}

We finally examine the extent to which differences in human P2P trading strategies impact SC, autarky, and electricity costs at the household and community level. To this end, we divided the sample in three groups based on participants' trading decisions in the experimental task. Specifically, we divided the normal distribution of prosumers' decision to sell (Shapiro-test $\mathrm{p}$-value $=0.2276$ ) between prosumers that only trade PV electricity rarely (those that are below $\mu-\sigma$ ), moderately (those between $\mu-\sigma$ and $\mu+\sigma$ ) and intensively (those that are above $\mu+\sigma$ ) (see Figure $3 \mathrm{~A}$ ). We then created three specific communities, each exclusively composed by the members of one of the three trader subsamples. Figure 3, depicts the boxplots for SC, autarky and annual bill of the households with PV and battery (B) and the overall community (C) for the three specific P2P communities. In line with our hypothesis, the figure points to an optimal trading window: moderate trading patterns ensure relatively high SC and autarky values at both levels, the individual (37\% and $70 \%$, respectively) and at the community (51\% and 50\%, respectively). This decision pattern also resulted in the highest economic benefits at the individual level (bill reduction of 46 and $43 €$ p.a. compared to restrained and intensive trading patterns), and at the community level (bill reduction of 1226 and $918 €$ p.a.). Moreover, the reduction in the maximum weekly average magnitude of the duck curve falls from $174 \mathrm{~kW}$ to $159.9 \mathrm{~kW}$ (i.e., a reduction of $8.2 \%$ compared to the self-consumption community). In contrast, restrained traders achieve high SC and autarky at the individual level (40.3\% and 79.3\% respectively), but provide less value for the community as SC and autarky at the community level decrease by 1 and 1.3 percent points respectively, compared to the moderate trading group. Moreover, the reduction in the maximum weekly average magnitude of the duck curve is 4.7 percent points less than in the moderate trading strategy. As a consequence of restrained trading, electricity prices in the local market become higher due to behaviour uniformity, which increases the community electricity costs overall (median value of $63680 €$ p.a.). In contrast, intensive traders are those who contribute the most to community SC and autarky, leading to increases 
in SC and autarky at the community level of 2.4 and 2.3 percent points compared to restrained traders and of 1.3 and 1 percent points compared to moderate traders. This trading pattern has also the highest potential to reduce the duck curve magnitude (i.e., 9.55\% compared to the self-consumption community, and 1.35 percent points higher than the moderate trading group). However, intensive trading reduces SC and autarky at the individual level, leading to decreases in both values of 10.7 and 23.7 percent points compared to restrained traders and of 7.6 and 14 percent points compared to moderate traders. As a consequence, intensive trading leads to situations where those prosumers have no electricity left in their batteries to cover their own demand and are forced to buy electricity at higher prices.

\section{Discussion}

Our study combining data from experimental psychological research with state-of-the-art energy modelling illustrates that social empowerment in $\mathrm{P} 2 \mathrm{P}$ communities may lead to multiple benefits for community members, encompassing prosumers as well as traditional consumers. Our analysis comes with four key implications for industry, policymakers and academics.

First, we find that traditional consumers are those who benefit the most from P2P electricity trading in terms of economic (bill reduction) and environmental advantages (renewable electricity access at a reduced price). The effects are driven by the fact that classic consumers have the highest bills and thus the largest reduction potential (see Figure 1). Considering that consumers do not have any upfront investment in PV nor storage systems, this result points to the need to consider fairness issues in the design of RECs and the energy transition in general. However, incentives for investments in renewable energy technology such as PV and storage systems are needed to ensure sufficient availability of renewable electricity at the local level ${ }^{29}$. Customised memberships fees (e.g., to cover network costs) depending on the type of participation, could enable a fair distribution of the P2P community inherent costs.

Second, we find that community autarky was overall lower in a self-consumption community compared to a P2P community based on actual decision preferences. We refer to this phenomenon as the autarky paradox illustrating the fact that a self-consumption community aiming to increase local autarky performs less well on this criterion than a more dynamic P2P community. In a P2P community, the more flexible exchange of locally generated electricity reduces export to and import from the upstream grid, eventually increasing autarky at the community level. Thus, a lower value of the SOC of batteries is reached in P2P communities throughout the year on a daily basis, which allows to further charge the battery with more self-generated PV electricity when the next surplus occurs. This higher activity of batteries in P2P communities should also result in lower battery lifetime and levelized cost associated with their performance. Thus, several benefits and risks of participation in $\mathrm{P} 2 \mathrm{P}$ communities need to be communicated in a transparent manner to avoid wrong promises.

Third, our analysis of grid impacts shows that the duck curve is flattened in P2P communities, reducing both, weekly average import and export peaks by $22 \%$ and $6 \%$, respectively, when compared with self-consumption communities, using always the same technologies, and through the creation of a local market. These findings suggest that P2P communities can reduce the duck curve at the local level throughout the year, which makes P2P communities an attractive solution to manage distributed PV for distribution system operators. P2P trading reduces the need to ramp up generation in the late afternoon, resulting in lower strain and costs for the grid. This reduction potential should be taken into account when networks costs as well as import/export tariffs are determined for P2P communities. However, extreme peak occurrences (export and import peaks) remain at similar levels in both types of communities. In order to further reduce the impact of distributed resources on the grid, incentives for flexibility, constraints on transfer capacity ${ }^{30}$ or more cost-reflective tariff structure, for instance, including capacity based tariffs, can be introduced ${ }^{31,32}$.

Fourth, our interdisciplinary analysis moreover shows that different decision-making strategies strongly affect performance indicators at the individual and community levels. Pointing to an optimal trading window, either too restrained or too intensive trading strategies lead to financial and autarky-related disadvantages at both levels. Our results pinpoint to a moderate trading strategy to maximise benefits, which interestingly, was applied by the majority of examined participants in the experimental study (see Figure 3). For the design of a P2P community, this finding means that responsible stakeholders should dare to involve community members in the development stages as well as in the operation of $\mathrm{P} 2 \mathrm{P}$ communities. Besides the finding that the majority of participants adapted beneficial decision strategies, stronger involvement can increase social empowerment which eventually may lead to co-benefits such as increased satisfaction, participation rates, and technology investments.

To conclude, this paper is a first study to compare P2P and self-consumption communities, combining data from experimental psychological research and technical community simulations, taking into account prosumer decision- 
making strategies. However, our study is not without limitations, which in turn call for future research. We propose four potential paths. First, alternative pricing mechanisms or more complex auction systems can be explored beyond our proposed community market price approach based on the balance between PV supply and demand. We, however, argue that these mechanisms should also consider prosumer preferences as input data. Secondly, here we propose a simulation approach that includes the exact answers from the survey, which allows us to recreate real-life decisions. However, it is an open question whether an optimization (and depending on its objective function) would yield better results at the three levels, individual, community and grid, while taking into account customer preferences. Thirdly, the inclusion of other indicators such as marginal emissions together with other low-carbon technologies such as electric vehicles and heat pumps should be analyzed in future research. Finally, our research emphasizes the need to discuss and analyse fairness issues in P2P communities to ensure long-term participation and needed investments in PV and storage infrastructure.

\section{Methods}

\section{Experimental online study}

Participants. In total, 254 homeowners participated in the study. Aiming for a representative sample of German homeowners, data collection was assigned to a market research institute (survey date: March 2020). As the data was collected during the COVID-19 lockdown in Germany, it might be possible that decision preferences were influenced by the temporal context (e.g., leading to more or less willingness to trade electricity ${ }^{33}$ ). However, comparison with existing data published before the pandemic show high similarities in decision patterns ${ }^{12}$. Demographic characteristics of the full sample are depicted in the SI, Table 1. The distribution of sex, age, educational level, and occupation reflected the entire population of German homeowners. Participants completed the study online and received financial compensation. The study was approved by the ethics committee of the Faculty of Psychology and Educational Sciences of the University of XXX, XXX (blind for review). All participants gave their consent to take part in the study.

Pre-assessment and P2P decision task. Participants first answered a series of demographic questions including sex, age, civil status, employment status, highest achieved educational degree, and household size. Participants were then introduced to the P2P energy trading scenario which we designed to reflect future conditions in a realistic and vivid manner. The decision scenario was adapted from a recently published study by Hahnel et al. ${ }^{12}$. In the illustrated scenarios (adapted from Ecker et al. ${ }^{34}$ ), participants were asked to image that they installed PV modules on the roof to generate electricity as well as a $10 \mathrm{kWh}$ battery in the basement to store the generated electricity. The PV system generated electricity for $11 €$ cents/kWh (based on the pay-off of the investment). Inside the community, participants were able to trade electricity from their batteries.

Subsequently, the choice task was introduced (see Figure 1 for a visualization of the task). Participants were instructed that they would face several independent situations in the described scenario and had to decide whether or not they want to sell electricity $(1 \mathrm{kWh})$ from their battery to the community. In each situation, they were informed about the projected next PV surplus, the range of the state of charge of their battery, and the price offered for electricity inside the community. Prior to the task, participants were informed that when their battery was empty they would have to buy their energy at the community market price at that moment (i.e., they become price-takers). Similarly, when their battery was fully charged they would have to sell their energy at the current market price. Afterwards, participants reported their willingness to participate in the described P2P community. When the answer was negative (i.e., 75 participants or 30\%), participants were asked for the reason and then the study was closed for those individuals (see Section 2.3 of SI). In the case of a positive answer, participants were forwarded to the energy trading section. That is, only participants willing to take part in a $\mathrm{P} 2 \mathrm{P}$ community were examined in this study, increasing the external validity of the findings.

P2P experimental design. The study was based on an $4 \times 3 \times 2$ within-subjects design with the different electricity prices being offered in the community ( $4 €$ cents $/ \mathrm{kWh}$ to $28 €$ cents $/ \mathrm{kWh}$ in steps of $8 €$ cents $/ \mathrm{kWh}$ ), SOC of the battery (30\%-90\% in steps of 30\%), and time until next surplus (more than or less than 12 hours). All possible combinations of price and charging states were presented in random order resulting in a total of 24 decisions. The dependent variable was participants' choices to either sell electricity from the battery or not.

During the task a reminder box was displayed informing participants that the production price was $11 €$ cents $/ \mathrm{kWh}$, that selling electricity would decrease the SOC of their battery by $10 \%$ (corresponding to $1 \mathrm{kWh}$ ), a full storage is sufficient to cover the electricity demand for one day, and that their decisions would be valid for an 1-h interval and could be revised afterwards. 


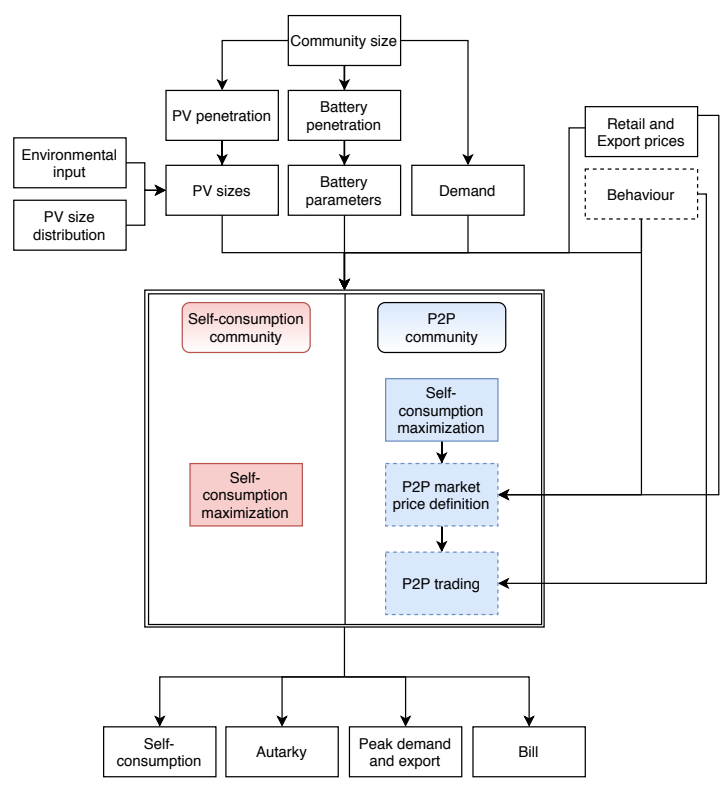

Figure 4. Schematic representation of the modeling approach proposed.

\section{Simulation}

Input data and assumptions. We use the distribution of PV sizes from the EEG register data and funding rates (which can be found here https://bit. $\left.1_{\mathrm{Y}} / 37 \mathrm{d0} 6 \mathrm{~L}\right)$ with 841783 registers of small PV plants $(\leq 10 \mathrm{~kW})$, from which we randomly generate, for each simulation, the PV size attached to each one of the households in the REC. The PV generation is modeled using outdoor temperature and clear sky global irradiation on horizontal plane at ground level in Munich, Germany from Soda-Pro (http: / /www. soda-pro.com/) for the year 2015 and a single diode equivalent circuit model. We generate one year data with 15 -minute resolution of a $1 k W_{p} \mathrm{PV}$ system that is afterwards scaled up to the PV size required for a given household. In accordance with the survey, we use a $10 \mathrm{kWh}$ battery system with $100 \%$ depth-of-discharge to facilitate the question formulation and understanding. In the cases where PV and batteries are included in one household, we use a DC-coupled topology (i.e., coupled on the direct current side) since the overall efficiency of stored PV electricity than in AC-coupled topologies. In terms of demand, we use electricity consumption data with 15-minute temporal resolution of 74 typical residential load profiles from a published German dataset ${ }^{35}$.

As for the electricity prices for the self-consumption community, we use a flat tariff of $28 €$ cents $/ \mathrm{kWh}$ as the retail price, which is close to the reported average retail price for households in Germany for the second half of 2019 (28.7 $€$ cents $/ \mathrm{kWh})^{36}$, since it is easier to communicate via the survey. The PV export price is assumed to be constant at 4 $€$ cents $/ \mathrm{kWh}$, which is close to the average German wholesale electricity price (3.8 €cents/kWh) for the years 2017-2019. This assumption is based on the Swiss case where new PV installations are paid at the wholesale price as are traditional electricity generators, and it is expected to become a widespread policy in other countries as a consequence of falling cost of PV technology. The retail and export prices are also the higher and lower limit of the P2P market price in the community, respectively.

Solar community model. The open-source model, schematically represented in Figure 4 is based on prosumpy, a toolkit for the simulation and economic evaluation of self-consumption and solar home battery systems $\mathrm{s}^{37}$, and takes as inputs the community size, PV and battery penetration, and the demand and generation datasets. The model and data on which this article builds up are available at https://github.com/alpebexo/solar_communities.

Self-consumption community. We model self-consumption communities as local communities (i.e., behind a point of common coupling), with a mix of prosumers with and without battery and traditional consumers, that trade electricity after having met their own demand (they prioritize self-consumption and autarky) and where a share of the prosumers have invested into a centralized battery that they can use. The traded electricity within the self-consumption community is paid to the seller at the export price (i.e., $4 €$ cents $/ \mathrm{kWh}$ ) and charged to the buyer at the retail price (i.e., $28 €$ cents $/ \mathrm{kWh}$ ). In order to verify the validity of our results, in Section 3 of the SI we implement a self-consumption community using the same pricing mechanism than in a P2P community. In this way, we confirmed that the P2P community perform 
better than self-consumption communities, even under similar price structure.

P2P community. Similarly, P2P communities are local communities with a mix of prosumers and traditional consumers. However, a local market is created and the electricity traded within the market is paid at the market price. When the community demand is met and there is a community surplus of electricity, the electricity is sold to the retailer at the export price (i.e., $4 €$ cents $/ \mathrm{kWh}$ ). In a similar way, when the community demand cannot be met by the local production, the retailer provides the required electricity at the retail price (i.e., $28 €$ cents $/ \mathrm{kWh}$ ). Each subject survey answer was allocated to a single household (with PV and battery), which was randomly selected and their actual choices were included in the simulation depending on the situational conditions (prices, battery SOC and time until the next surplus).

Pricing mechanism in P2P community. The difference between the market price inside the $\mathrm{P} 2 \mathrm{P}$ community and both, the retail price and the export price, provides the fundamental incentive for community members to participate in the P2P community. In this way, the higher the difference between the retail price and the P2P market price is, the higher the incentive for the community to consume local energy. In the same way, the higher the difference between the export price and the $\mathrm{P} 2 \mathrm{P}$ market price is, the higher the incentive for the prosumers to sell local energy. The market price is defined by the electricity supply and demand at each timestep (based on the supply demand ratio ${ }^{17}$ ), which is approximated to one of the four prices proposed in the survey (i.e., 4, 12, 20 and $28 €$ cents/kWh). Therefore, the market price is constrained to be a step function, with the export price as lower bound and the retail price as the highest one ${ }^{17}$.

Community conformation. We focus on communities with 100 members, which is a typical number of houses connected to a low voltage substation in some European countries ${ }^{38}$. We use $50 \%$ PV penetration (i.e., 50 households with PV) and 25\% battery penetration (i.e., out of the 50 households with PV, 25 have as well access to a battery) for the main analysis. Analysis of other PV and battery penetration (25 and $75 \%$ for each one) scenarios and community sizes $(20,40,60$ and 80) are shown in the Supplementary Information. At the community level, we found an important impact of PV and battery penetration in the community, whereas the community size impact is reduced at both levels. As PV and battery penetrations increase, the autarky at the community level increases, while the self-consumption and the annual bill reduce, which suggest a saturation beyond a given threshold of technology penetration, which remains to be studied. Our proposed open-source model allows to easily modify the community size as well as the PV and battery penetration.

KPI definition. To evaluate the performance of the communities we use two economic indicators as well as three technical indexes. Firstly, we use the individual bill (Eq. 1) and the aggregated bill for the community (Eq. 2). The second economic indicator is the participation willingness index ${ }^{18}$, which measures the percentage of the prosumers who obtain more benefits after participating in a community energy sharing mechanism, reflecting the overall participation willingness of the whole population (Eq. 3). However, in this study we renamed this index as the "benefit index", since we consider that "participation willingness index" can be mistaken with the willingness of the survey participants to be part of the proposed P2P community.

$$
\begin{aligned}
& \text { Bill }_{j}=\sum_{i=0}^{t}\left(E_{\text {grid-to-house }_{i}} \cdot \pi_{\text {retail }_{i}}-E_{\text {house-to- }_{\text {com }}} \cdot \pi_{\text {export }_{i}}\right) \\
& \text { Bill }_{\text {com }}=\sum_{j=0}^{N}\left(\text { Bill }_{j}\right) \\
& B I=N_{\text {LowerCost }} / N
\end{aligned}
$$

Where, for the household $\mathrm{j}$ at time i, $E_{\text {grid-to-house }}$ is the amount of energy consumed and $E_{\text {house-to-grid }}$ is the amount of energy shared with the community, $\pi_{\text {retail }}$ and $\pi_{\text {export }}$ are the retail and export price respectively, which in the case of the $\mathrm{P} 2 \mathrm{P}$ community both are equal to the $\mathrm{P} 2 \mathrm{P}$ market price. The community bill is the aggregation of the individual bills across the $\mathrm{N}$ members of the community. It is worth to highlight that in both cases we do not consider any cost associated to the community membership. In Eq. $3, N_{\text {LowerCost }}$ represents the number of prosumers with a lower energy cost when they are in the $\mathrm{P} 2 \mathrm{P}$ community compared to the cost in the self-consumption community. The higher the $\mathrm{BI}$ value, the higher participation willingness. 
In terms of technical performance, we use the indicators self-consumption (SC), which is the share of on-site PV generation that is used to cover the electricity demand and autarky, which is the share of total demand that is covered by the on-site PV generation, at both levels, the individual and the community, as defined in Eqs. 4 and 5. We graphically visualize these two indicators in an energy matching chart ${ }^{26}$.

$$
\begin{aligned}
& S C=\sum_{i=0}^{t} \frac{E_{P V-\text { demand }_{i}}+E_{P V-\text { batt }_{i}}}{E_{P V_{i}}} \\
& \text { autarky }=\sum_{i=0}^{t} \frac{E_{P V-\text { demand }_{i}}+E_{P V-\text { batt }_{i}}}{E_{\text {demand }_{i}}}
\end{aligned}
$$

At the community level and to account for the interaction with the grid, we use the peak-to-peak amplitude difference, in order to measure the daily variance of the interaction with the grid, in particular, the so-called duck curve. The peak-to-peak amplitude difference measures the distance between the lower peak (maximum export of the day) and the higher peak (maximum import of the day), which in graphical terms is the distance from the bottom to the top of the duck head (in kW, see Figure 2A). This indicator allow us to highlight the differences between the two types of communities beyond the year maxima.

Statistical tests. To highlight statistically significant differences across the results, we perform a Shapiro-Wilk test to prove non-normality of the results, followed by a paired Wilcoxon test with Holm procedure to control the family-wise error rate. When more than two samples were compared, we used a Kruskal-Wallis test.

\section{References}

1. European Union. Directive (eu) 2018/2001 of the european parliament and of the council of 11 december 2018 on the promotion of the use of energy from renewable sources. Off. J. Eur. Union 5, 82-209 (2018).

2. Carlisle, N., Elling, J. \& Penney, T. Renewable energy community: Key elements. Tech. Rep., National Renewable Energy Lab.(NREL), Golden, CO (United States) (2008).

3. Council of European Energy Regulators. Regulatory aspects of self-consumption and energy communities. Tech. Rep., Council of European Energy Regulators, Brussels, Belgium (2019).

4. Roberts, J., Frieden, D. \& d'Herbemont, S. Energy community definitions. Deliv. Dev. Under Scope COMPILE Proj. Integrating Community Power Energy Islands (H2020-824424) (2019).

5. Parra, D. et al. An interdisciplinary review of energy storage for communities: Challenges and perspectives. Renew. Sustain. Energy Rev. 79, 730-749 (2017).

6. Sardi, J., Mithulananthan, N., Gallagher, M. \& Hung, D. Q. Multiple community energy storage planning in distribution networks using a cost-benefit analysis. Appl. energy 190, 453-463 (2017).

7. Devine-Wright, P. Community versus local energy in a context of climate emergency. Nat. Energy 4, 894-896 (2019).

8. Koirala, B. P., Koliou, E., Friege, J., Hakvoort, R. A. \& Herder, P. M. Energetic communities for community energy: A review of key issues and trends shaping integrated community energy systems. Renew. Sustain. Energy Rev. 56, $722-744$ (2016).

9. Ableitner, L. et al. User behavior in a real-world peer-to-peer electricity market. Appl. Energy 270, 115061 (2020).

10. Lüth, A., Zepter, J. M., del Granado, P. C. \& Egging, R. Local electricity market designs for peer-to-peer trading: The role of battery flexibility. Appl. energy 229, 1233-1243 (2018).

11. Parag, Y. \& Sovacool, B. K. Electricity market design for the prosumer era. Nat. energy 1, 1-6 (2016).

12. Hahnel, U. J., Herberz, M., Pena-Bello, A., Parra, D. \& Brosch, T. Becoming prosumer: Revealing trading preferences and decision-making strategies in peer-to-peer energy communities. Energy Policy 137, 111098 (2020).

13. Hackbarth, A. \& Löbbe, S. Attitudes, preferences, and intentions of german households concerning participation in peer-to-peer electricity trading. Energy Policy 138, 111238 (2020). 
14. Reuter, E. \& Loock, M. Empowering local electricity markets: A survey study from switzerland, norway, spain and germany. Empowerh2020 (2017).

15. Andoni, M. et al. Blockchain technology in the energy sector: A systematic review of challenges and opportunities. Renew. Sustain. Energy Rev. 100, 143-174 (2019).

16. Wörner, A. et al. Trading solar energy within the neighborhood: field implementation of a blockchain-based electricity market. Energy Informatics 2, 11 (2019).

17. Liu, N. et al. Energy-sharing model with price-based demand response for microgrids of peer-to-peer prosumers. IEEE Transactions on Power Syst. 32, 3569-3583 (2017).

18. Zhou, Y., Wu, J. \& Long, C. Evaluation of peer-to-peer energy sharing mechanisms based on a multiagent simulation framework. Appl. energy 222, 993-1022 (2018).

19. McCollum, D. L. et al. Interaction of consumer preferences and climate policies in the global transition to low-carbon vehicles. Nat. Energy 3, 664-673 (2018).

20. Wolinetz, M., Axsen, J., Peters, J. \& Crawford, C. Simulating the value of electric-vehicle-grid integration using a behaviourally realistic model. Nat. Energy 3, 132-139 (2018).

21. Hahnel, U. J., Chatelain, G., Conte, B., Piana, V. \& Brosch, T. Mental accounting mechanisms in energy decisionmaking and behaviour. Nat. Energy 1-7 (2020).

22. Tiefenbeck, V. Bring behaviour into the digital transformation. Nat. Energy 2, 1-3 (2017).

23. Ahl, A., Yarime, M., Tanaka, K. \& Sagawa, D. Review of blockchain-based distributed energy: Implications for institutional development. Renew. Sustain. Energy Rev. 107, 200-211 (2019).

24. Secretariat, R. Renewables 2020 global status report. Rep. Paris: REN12 (2020).

25. Kosowatz, J. Energy storage smooths the duck curve. Mech. Eng. 140, 30-35 (2018).

26. Luthander, R., Nilsson, A. M., Widén, J. \& Åberg, M. Graphical analysis of photovoltaic generation and load matching in buildings: A novel way of studying self-consumption and self-sufficiency. Appl. Energy 250, 748 - 759 (2019). [Accessed on 18/05/2020].

27. Gupta, R. et al. Spatial analysis of distribution grid capacity and costs to enable massive deployment of pv, electric mobility and electric heating. Appl. Energy (2021).

28. Heptonstall, P. J. \& Gross, R. J. A systematic review of the costs and impacts of integrating variable renewables into power grids. Nat. Energy 1-12 (2020).

29. IRENA, O. et al. Renewable energy policies in a time of transition, irena oecd/iea ren21 (2018).

30. Heinisch, V., Odenberger, M., Göransson, L. \& Johnsson, F. Organizing prosumers into electricity trading communities: Costs to attain electricity transfer limitations and self-sufficiency goals. Int. J. Energy Res. 43, 7021-7039 (2019).

31. Morstyn, T., Farrell, N., Darby, S. J. \& McCulloch, M. D. Using peer-to-peer energy-trading platforms to incentivize prosumers to form federated power plants. Nat. Energy 3, 94-101 (2018).

32. Almenning, O. M., Bjarghov, S. \& Farahmand, H. Reducing neighborhood peak loads with implicit peer-to-peer energy trading under subscribed capacity tariffs. In 2019 International Conference on Smart Energy Systems and Technologies (SEST), 1-6 (IEEE, 2019).

33. Fell, M. J. et al. Validity of energy social research during and after covid-19: challenges, considerations, and responses. Energy Res. \& Soc. Sci. 68, 101646 (2020).

34. Ecker, F., Spada, H. \& Hahnel, U. J. Independence without control: Autarky outperforms autonomy benefits in the adoption of private energy storage systems. Energy Policy 122, 214-228 (2018).

35. Tjaden, T., Bergner, J., Weniger, J., Quaschning, V. \& Solarspeichersysteme, F. Repräsentative elektrische lastprofile für wohngebäude in deutschland auf 1-sekündiger datenbasis. Hochschule für Tech. und Wirtschaft HTW Berlin (2015).

36. Eurostat. Household energy prices in the eu increased compared with 2018. News release (2020). 
37. Quoilin, S., Kavvadias, K., Mercier, A., Pappone, I. \& Zucker, A. Quantifying self-consumption linked to solar home battery systems: Statistical analysis and economic assessment. Appl. Energy 182, 58-67 (2016).

38. Pimm, A. J., Cockerill, T. T. \& Taylor, P. G. Time-of-use and time-of-export tariffs for home batteries: Effects on low voltage distribution networks. J. Energy Storage 18, 447-458 (2018).

\section{Acknowledgements}

blind for review

\section{Author contributions}

blind for review

\section{Competing interests}

The authors declare no competing interests.

\section{Code and data availability}

The code and data that support the findings of this study are available in https://github.com/alpebexo/ solar_communities and 10.5281 /zenodo.4531409, respectively.

\section{Supplementary information}

Supplementary information accompanies this paper at doi XX 


\section{Figures}

\section{Household level}
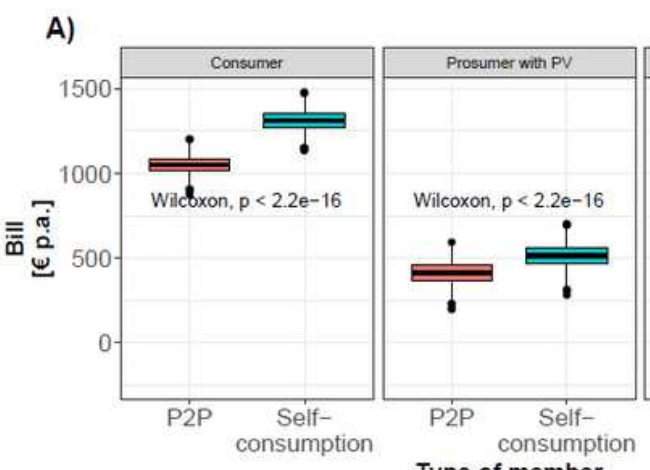

Type of member
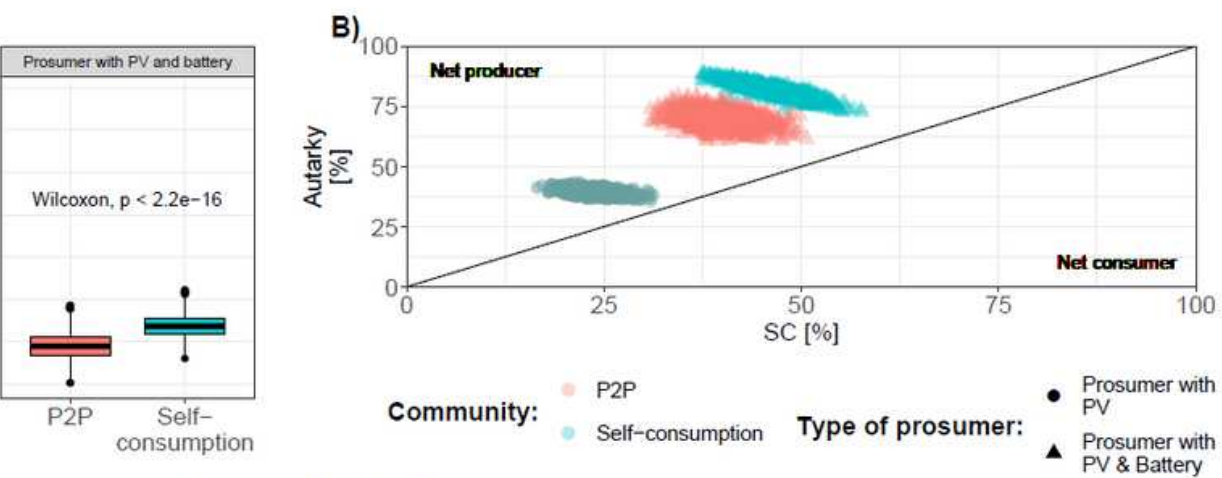

P2P

Self-consumption

Type of prosumer:

Prosumer with

Prosumer with PV \& Battery

\section{Community level}
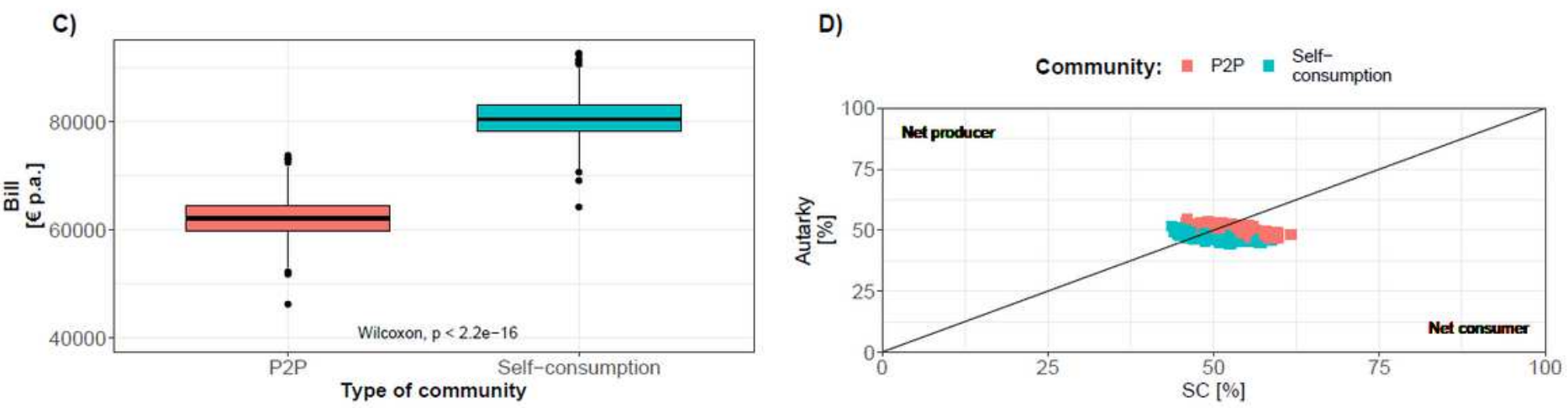

\section{Figure 1}

Results of the community modeling including prosumer preferences in P2P communities $(N=1000)$ : $A)$ Annual bill at the individual level depending on the type of the community member; B) Energy matching chart (i.e., a graphical approach to assess matching between PV electricity generation and electricity demand, using self-consumption and autarky to visualize improved matching with energy storage and load shifting) at the individual level; C) Aggregated bill at the community level; D) Energy matching chart at the community level. The diagonal line represents the net zero energy households. Net producers of electricity are above the line and net consumers are below. 
A) Average grid exchange in one week

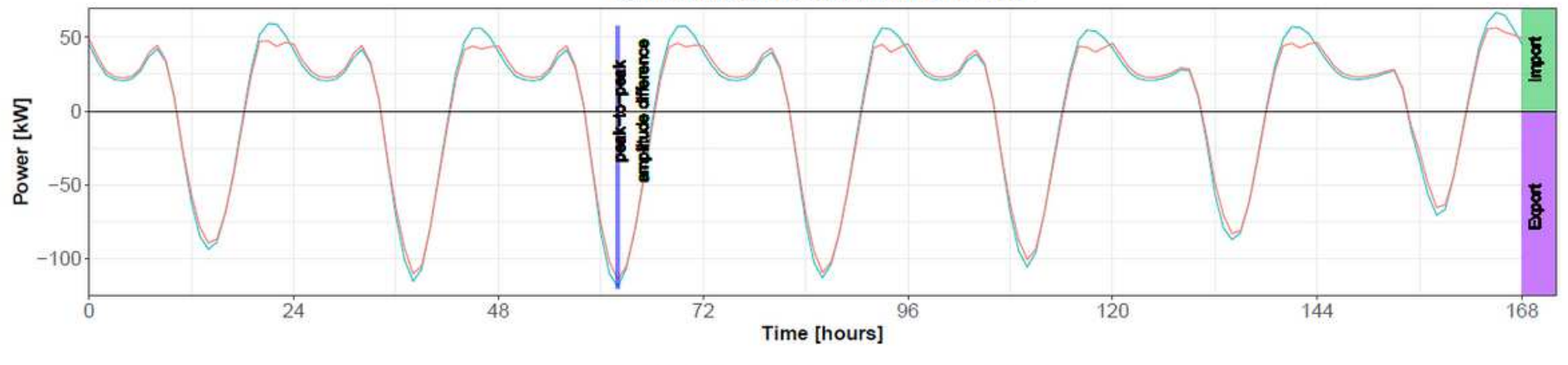

Community: - P2P - Self-consumption
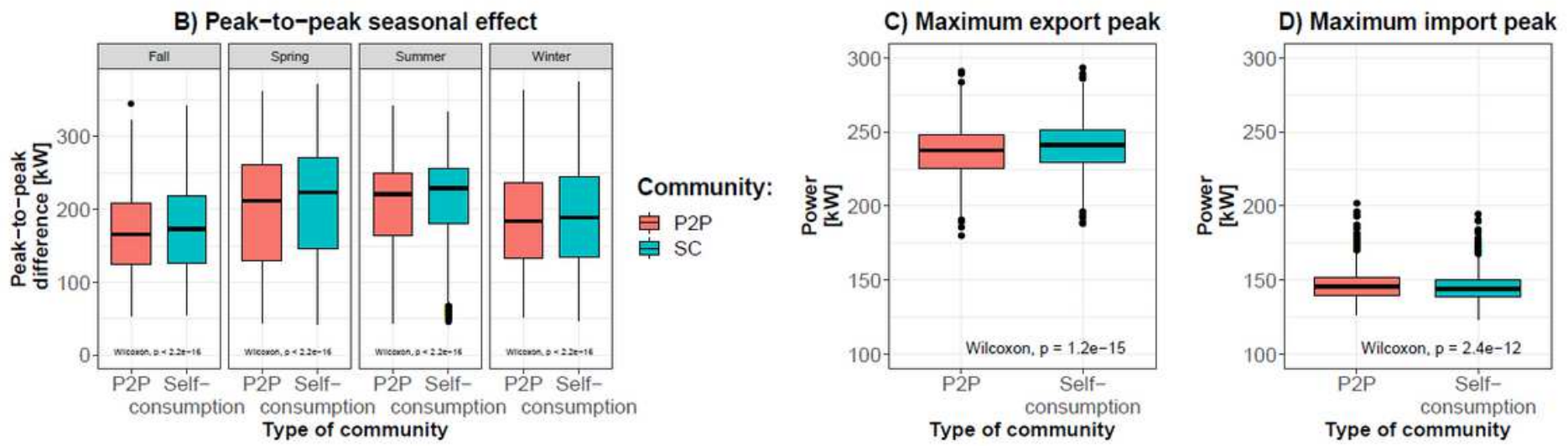

\section{Figure 2}

Grid exchange results: A) Average weekly results for one randomly selected simulated community and peak-to-peak amplitude difference to illustrate the duck-curve. Note that electricity exports are displayed in the negative $y$-axis. ; B) Seasonal effect in grid exchange, using the peak-to-peak amplitude difference for every day of the year $(\mathrm{N}=1000)$; $\mathrm{C}$ ) Maximum export peak throughout the year for every simulation $(\mathrm{N}=1000) ; \mathrm{D})$ Maximum import peak throughout the year for every simulation $(\mathrm{N}=1000)$. 
A) Trading decisions

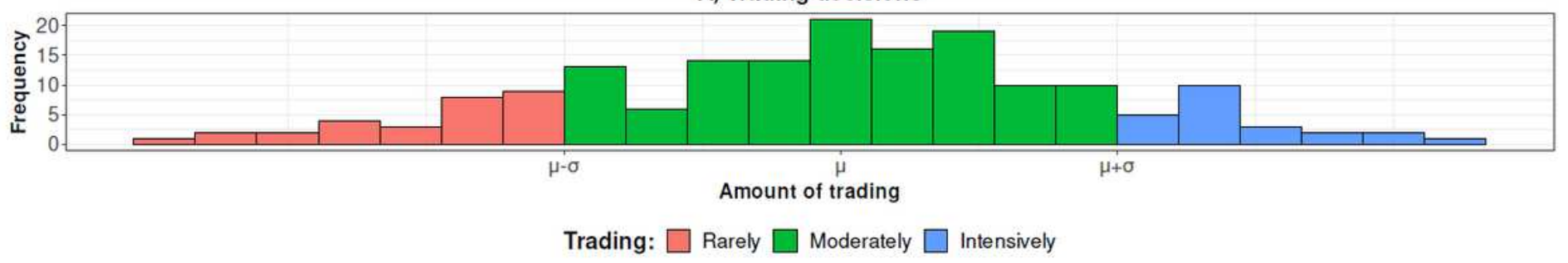

B) Households with PV and battery

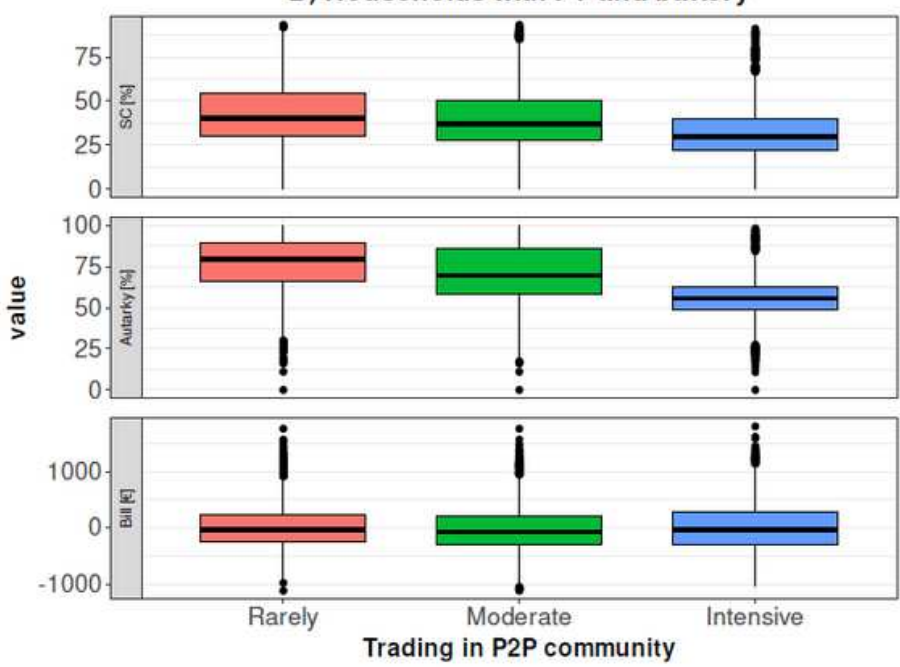

C) Community level

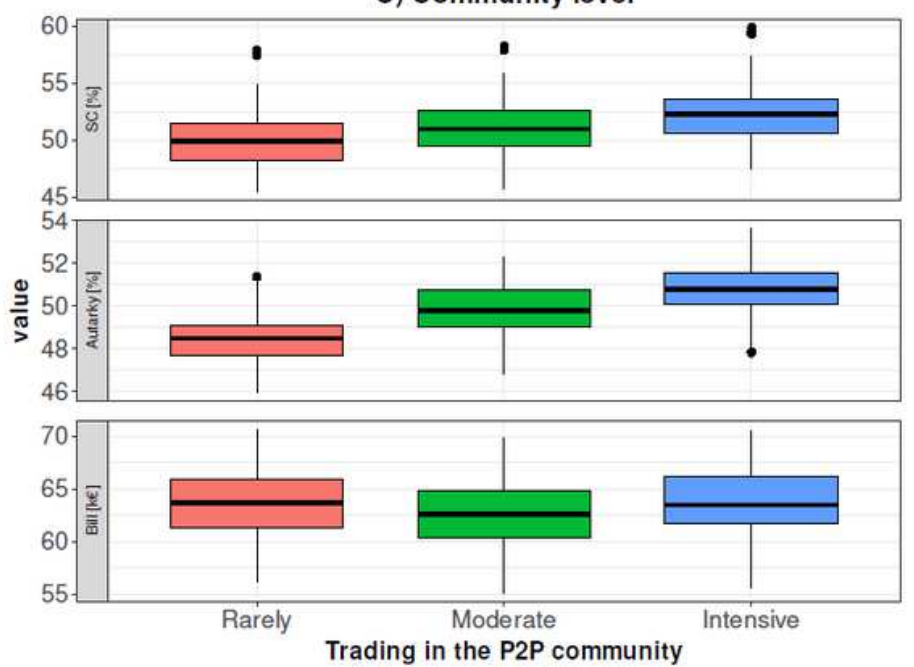

\section{Figure 3}

Results of the community modeling for communities with different patterns of trading $(N=100)$ : $A)$ Histogram of trading decisions extracted from the survey; B) Self-consumption, autarky and annual bill for households with PV-coupled batteries; C) SC, autarky and annual bill at the community level. 


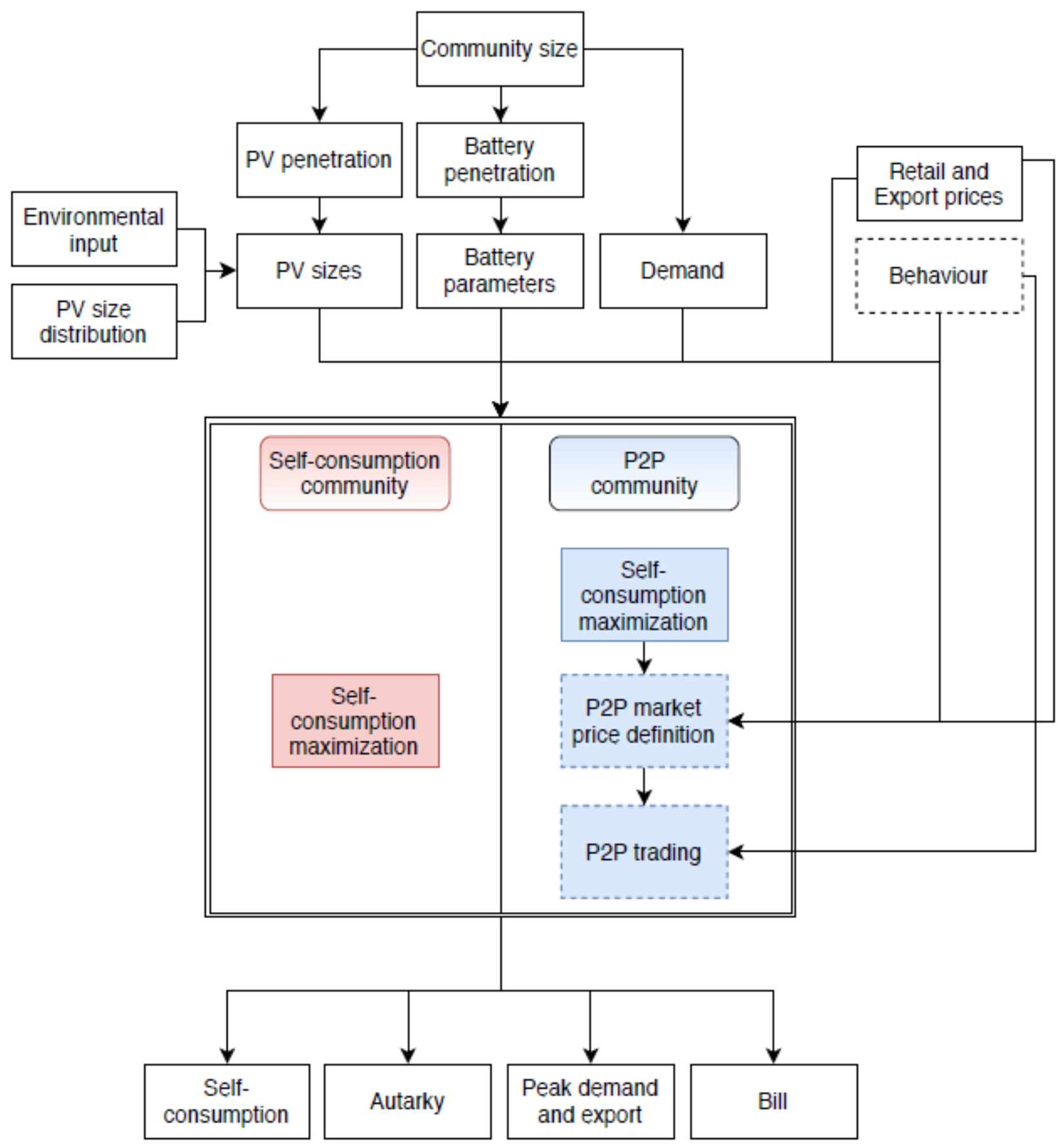

Figure 4

Schematic representation of the modeling approach proposed.

\section{Supplementary Files}

This is a list of supplementary files associated with this preprint. Click to download.

- EmpoweringprosumersSI.pdf 